Professor JAmes Thomson, transmitting through the Secretary his remarks, premised that the problem of how to provide good means for warming and ventilating any such set of rooms as those comprised in the buildings of a college, or a university, was a difficult one. Information in respect to a large undertaking of this kind was very important, whether to serve as a guide for showing courses which might advantageously be followed in future, or as a beacon for indicating what should be avoided. $\mathrm{He}$ said the arrangements carried out for warming and ventilating in Glasgow University were to be regarded as only in a moderate degree successful. They were far from admitting of being contemplated with satisfaction, and this for various reasons. In the class-rooms of several of the large classes the scheme turned out to be quite inadequate as to ventilation. In some of them, which were crowded with students, after strong complaints of the oppressiveness of the air, it had become necessary to have recourse to the opening of windows in winter weather to mitigate the evil. But the opening of the windows completely subverted the intended ventilation arrangements, and rendered them in the main nugatory. Such results, he said, inevitably must be entailed by the abandonment, in the executed scheme, of the originally intended essential arrangement, that besides the hot fresh air, cold fresh air should be supplied to each class-room, with means for mixing it. ${ }^{1}$ The abandonment of this provision was a mistake fatal to the success of the scheme; and if the adoption of the provision would have proved too difficult, it would have been better to have dropped the scheme as a whole, and to have entered on designs for the undertaking in some other way altogether. To ventilate a crowded class-room, new air must be supplied, amounting in volume to many times the contents of the class-room per hour. But if this air for ventilation is supplied hot from a system of conduits suitable for warming other class-rooms before the meeting of the students, or class-rooms with only a few occupants, the temperature in the crowded rooms must necessarily become intolerably high. The bodies of the occupants, with their breathing included, would make the room very hot, and would render the air badly vitiated, unless a large flow of new air were maintained, passing through the room in such way as to scour off the vitiated air from around them. Now obviously the air to be supplied for a crowded meeting must enter in large quantity, and at no higher tem-

1 Vide No. 5 of the original recommendations of the Committee of Professors cited by Mr. Phipson near the beginning of his Paper. 
perature than that of air desirable for surrounding the occupants, and for being breathed by them. But the air in the ducts which lead to some of the crowded rooms is, he said, ordinarily at about from $90^{\circ}$ to $109^{\circ}$ Fahrenheit, and some such temperature is requisite to provide sufficient warming effects in other rooms. In several of the class-rooms the hot ventilation air comes in by openings about half-way up the walls, and goes away in great part by passing clear over the heads of the occupants to wall-head outlets, without ever coming down for the use of the occupants, the cooler air tending to stagnate around them in the lower half of the room.

In the Paper the Author had stated that he " based the calculations of the size of all air passages, \&c., both for outlet and inlet of the air, on a supply equal to six times the cubical space of the class-rooms in the hour as a minimum, or about 750 cubic feet per hour, per sitting." Now Prof. Thomson presumed that if this amount of ventilation by fresh air of suitable temperature were actually effected in the individual class-rooms, it would be unlikely that professors and students would make the complaints they did of deficient or faulty ventilation. He did not think, however, that any such supply is really given to the individual class-rooms generally. Last winter, for instance, in consequence of great complaints as to the ventilation of some of the crowded class-rooms, he was requested, with some of his colleagues, to act as a committee to examine into the subject. No exact quantitative experiments were made. The effort was rather, by examining into a fow doubtful points as to the behaviour of the air, and as to the effects of opening or closing some of the valves or other passages, to find whether any palliative improvements could be devised or effected. A set of observations thus made, in one of the class-rooms specially complained of, happened to give clear in dications which showed the change of air available to be very small indeed, in comparison with any such standard as 4, 5, or 6 times the volume of the class-room per hour. There were six inlet openings, about half-way up the walls of the room, for the admission of the ventilation air supply, which was warm as usual, and there were two valves near the ceiling for outlets, in addition to outlets in the risers under the students' seats. Smoke was produced by the burning of cotton waste or the like in a pan held up above the lecture-table. The wall-top outlets were left open for a considerable period, in order that the conditions and actions of the air so resulting might be found. The smoke arranged itself so as to form a well-marked thin stratum, which remained persistently at the level of the inlet orifices for the warm air, and [1878-79. N.s.] 
the result was obvious, that the warm ventilation air was floating like a canopy over the region to be occupied by the students and professor, and passing away by the wall-head outlets, while the original cold air remained stagnant in the lower part of the room. The wall-top outlets were afterwards closed, and then it was found that the cloudy stratum of smoke descended slowly, at some such rate as 2 feet in eight minutes. At any such rate as this, a long time would elapse, far more than an hour, before the contents of the class-room would be even once cleared out by the ventilation supply.

This, he said, was not offered as a very exact experimental result, nor as one tested by repetition for its confirmation; but he thought it was trustworthy enough to justify its being regarded as affording important indications. The smoky layer obviously indicated the level face of meeting of the cold stagnant air below, with the warm air floating above and passing from the inlets to the outlets while floating above the region to be occupied by the assemblage of people. Observations with thermometers above and below the smoky layer confirmed the view here stated.

The scheme as carried out, he said, involves the very objectionable feature that the air is conveyed through underground tunnels, of which the roof, the walls, and the bottom are thoroughly damp, and the bottom is in many places running with water. The entrance of moisture is especially objectionable in the hot-air tunnels. In some of these, water gathers at seasons when the heating is not maintained; but during the time of the College Session it is evaporated, and the subsequent accessions of water are also evaporated, so that the whole water passes with the ventilation air into the rooms. In one of these hot-air ventilation ducts, through which he had crept for inspection a few days previously, the floor was thoroughly covered with scale upon scale of pellicles obviously left behind by sheets of water, which, containing lime in solution, had successively dried up. Great evil had been experienced in the library and some neighbouring rooms from damp introduced in this way; but some amendments had lately been introduced in the arrangements for that part of the building. A very wet hot-air tunnel or chamber had, he understood, been drained, and some other changes had been made for abating the evil.

As a general rule, he asserted that the conveying of ventilation air by underground passages is highly objectionable, or gravely open to distrust. When this mode of conducting the air is taken, it is often impossible to make quite sure against the intrusion of foul emanations, gaseous or liquid, from sewers directly, or from 
ground or shingle permeated by water and air of sewers. Indeed the scheme carried out for the University of Glasgow, he said, had not altogether escaped from exemplifying the unsuitableness of subterranean ventilating passages in this respect. At one time foul air had been met with in the building, and it was then found that under the ventilation tunnel there had been left an old sewer which had belonged to the dwelling-house of Gilmore Hill before the lands were acquired for the University, and that an opening had been casually made into that sewer, whereby the foul air had been admitted into the ventilation air for the building. This was of course immediately remedied, and he presumed there had since been no indication met with of the admission of foul air to any part of the ventilation ducts.

In conclusion, he had to say that while the arrangements carried into effect for warming and ventilating in the University of Glasgow were such as he could not recommend for imitation in other places, yet he would wish it to be borne in mind that unsatisfactory results in warming and ventilating were the rule, and not the exception, in public buildings, as also in dwelling-houses, throughout the world.

The problem of devising good warming and ventilating arrangements for such a set of buildings and apartments as those of a University, where large classes of students are in attendance on lectures, and engaged in practical work in laboratories and in other ways, he said had not yet been well solved.

Dr. Allen Thomson said he should have scarcely ventured to speak upon a subject so foreign to all his knowledge and occupations, but for the circumstance that he had been the Chairman of the Building Committee of the Glasgow University during the construction of the apparatus which had been described. Indeed, from the year 1863 till the time that he left the University, more than a year ago, he had been to a certain degree in charge of the operations going on there, and he might therefore be supposed to know something of the apparatus in question, although he could scarcely pretend to any knowledge of the subject of ventilation and heating of buildings, at least practically; and he would be extremely averse to offer any decided opinion on a subject of such extreme difficulty. The result of his limited experience had been to confirm the remark of his former colleague, Professor James Thomson, that the problem of ventilating and heating (especially ventilating and heating together) large buildings had not yet been solved. At all events he would go so far as to say, that the application of such a mode of heating and ventilation as had been 
described should be regarded very much in the light of a great experiment. He would not, however, go the length of condemning the plan and apparatus as Professor James Thomson had done; he was rather inclined to give a different verdict with respect to it, and he thought that some of his colleagues, who had more knowledge of the subject than he had, would agree with him in saying that the Author's application of General Morin's system had been attended with considerable success. He was aware that a number of circumstances in the original construction had somewhat interfered with that success. The circumstance that the system was not matured until the whole of the plans of the building and drainage had been already set on foot, interfered considerably with the successful carrying out of some of the plans of the ventilating engineer, and it was only right to state that the same circumstance added largely to the original expense of the construction. With reference to the success of any general system of heating and ventilation, it was obvious that great variability was one of its most important attributes; and if he were to venture to criticise this one, it would be to say that it was too extensive, or too much upon one uniform plan throughout the whole building. One conclusion which he should be disposed to draw from the experiment was, that the modes of heating and ventilation should be very different according to the purposes that were to be served by the several parts of the building to which they were applied. In all such buildings there was a great distinction between class-rooms and halls for meeting on the one hand, and museums and libraries on the other; and he thought it was an original error on the part of the Sub-Committee of Professors to apply the system to the libraries and museums. With reference to the class-rooms and halls for meeting (and in this he believed that a majority of the Professors who were conversant with the management of the building would express the same opinion), the plan had been followed with good results. He was not aware of the experiments that Professor Thomson had described in his communication. They certainly appeared to indicate some defect in the room to which he had referred, but had not named. That was not in accordance with his own experience with respect to most of the class-rooms. On the contrary, he should be inclined to say with reference to other class-rooms which he had known, that the quality of the air was most satisfactory; that there was generally comfort with regard to heat, and freshness of air ; and that the health of the students had been extremely good. Those circumstances appeared to be in favour of the mode of combined heating and ventilation, by the forced introduction and extraction of air, in places resorted 
to by a large body of students. He was partially aware of the defect to which Professor Thomson had referred in one of the class-rooms. He presumed it was the Latin class-room, in which there were upwards of three hundred students. He believed that the inlets and outlets in that class-room were not calculated for so large a number, and that both increased force of introduction and increased size of the apertures would be required in order to provide proper ventilation for the room. That, however, should be considored as an exceptional case. He agreed with Professor Thomson that it was greatly to be regretted that the plan of combining the introduction of warm and cold air had not been followed out. On the whole he should be inclined to apply in museums and libraries, in which large numbers of persons were not to be congregated, a system of heating which would give gentle warmth, such as that derived from coils or other forms of wide hot-water pipes, within the rooms themselves, not attended with the introduction of large bodies of air from without. In the case of museums, the latter plan was especially to be avoided, on account of the difficulty of controlling dust and moisture.

Mr. Constantine said that the Paper had involved a great deal of patient research. The instructions of the Sub-Committee of Professors to the architect appeared to have been based upon General Morin's theory, which was a very complicated one. However good it might be for warming buildings, it had broken down in summer when a great quantity of fresh air was required. The expense of carrying out the plan was stated to be $£ 17,000$. $\mathrm{He}$ had recently the warming of the Manchester Pantechnicon, comprising fifty-four rooms, and the Royal Exchange, and he was able to say, after a very close calculation, that the cost of warming and ventilating such a building as the Glasgow University, instead of being $£ 17,000$, ought to have been $£ 1,360$. If what might, for the sake of distinction, be termed a natural system of ventilation had been carried out, with efficient air-warmers placed in different parts of the building, the warm air channels would act as fresh air ducts, and an ample supply of fresh air would have been obtained during the summer, which was a most important consideration. The system of coils, with a fan and an engine to drive the air, was a very expensive mode of introducing it. When the Royal Exchange at Manchester was planned, it was intended to force the air in by an engine and fan; but when the building was in course of erection, the architects asked him what he would suggest. That was soon after he had warmed the Free Trade Hall. Two convoluted stoves were fixed in the basement, where the cngine and fan were intended to be erected, and drew the fresh air from a 
height of 100 feet at the top of the building, and the system acted simply and easily. The ventilating and warming arrangements were shown in Fig. 1. Under the basement floor was a flue 3 feet

Frg. 1.

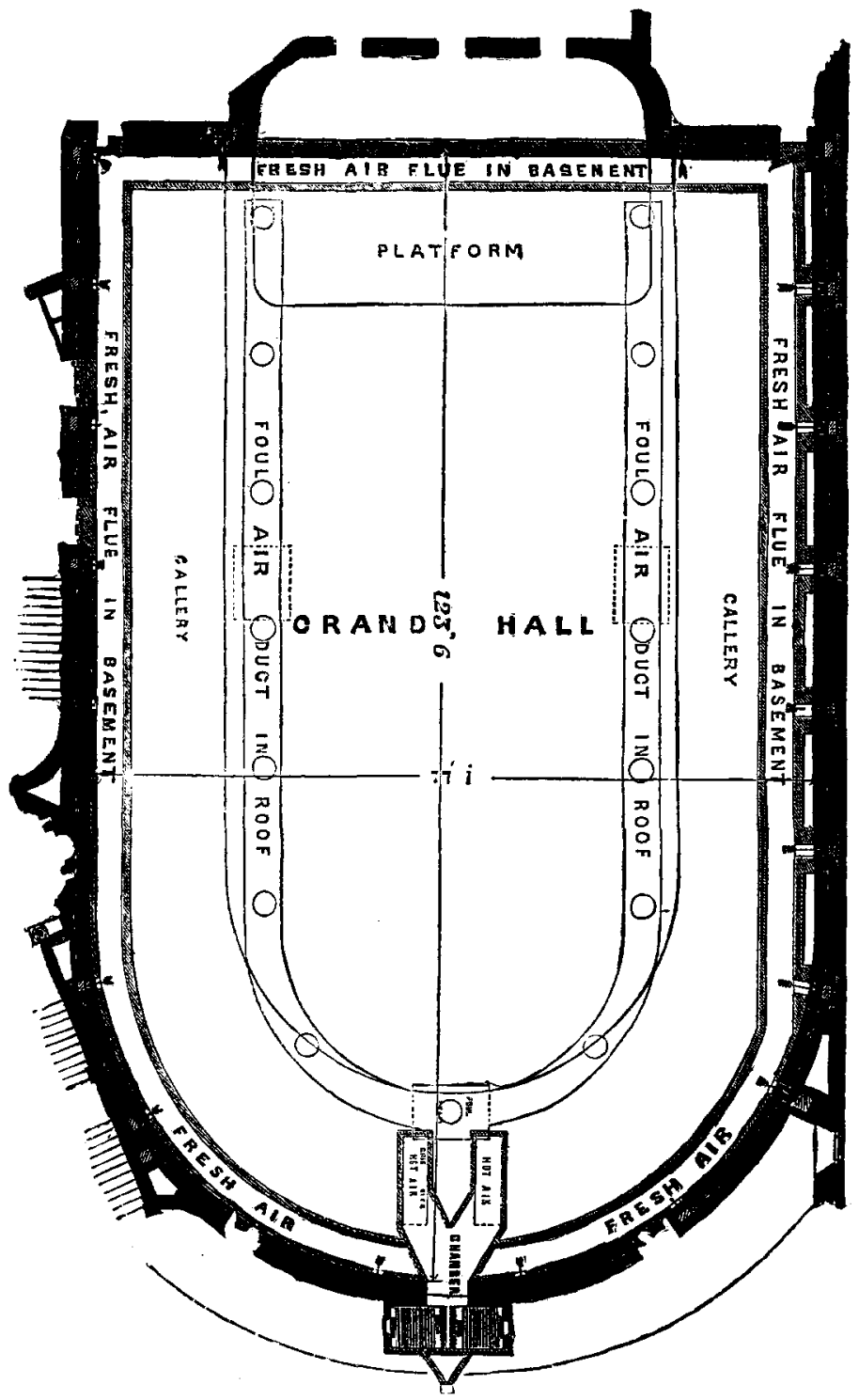

Plan of the Free Trado Hall, Manchester. 
broad by 2 feet 2 inches wide, directly supplied with fresh air from the outside. From this flue were carried up eighteen vertical shafts, each 2 feet by 1 foot 2 inches in the thickness of wall, delivering fresh air above the heads of the people in the gallery. For the extraction of the vitiated air, openings were provided round the fifteen sunlights into two lath-and-plaster ducts, measuring each 4 feet 3 inches broad by 3 feet 9 inches wide, along the inside of roof, uniting at end opposite platform into an upright shaft 7 feet 9 inches broad by 5 feet 7 inches wide inside. This main shaft was surmounted by a cowl moved easily by the wind, and had only the movable portion exposed above the roof. The inlet of fresh air was ample; but the exit for foul air was contracted, the cowl having only about the sectional area of one of the two ducts which it cleared. Although the warm air was all delivered in one place, in a few minutes the temperature was the same all over the hall. The temperature for the class-rooms was about equal to what was maintained in the Royal Exchange. The temperature given in the table was too low for class-rooms. In the first year the temperature in the class-rooms was only $16 \frac{3}{8}^{\circ}$ above that of the external air, and in the second year $17 \frac{1}{2}^{\circ}$. It ought to be raised $25^{\circ}$ in order to make the rooms thoroughly comfortable in severe winter weather. It appeared that 2 tons $3 \mathrm{cwt}$. of fuel was consumed per day, the number of cubic feet to be dealt with being 2,035,000. In the Royal Exchange the number of cubic feet were 1,500,000, for which $2 \frac{1}{2} \mathrm{cwt}$. of coke per day were sufficient. Supposing the building to be warmed by four large convoluted stoves it would not consume more than $5 \mathrm{cwt}$. of coke. The immense shafts were not absolutely necessary. Perhaps the best illustration of what might be called the natural system was in the Free Trade Hall, where an ample supply of fresh air was obtained during the summer months. He had brought a model of the convoluted stove, and should be glad to show the plans to any member who desired to see them.

Dr. Allen Thouson desired to add that he thought the Author had underrated the bulk of the building. He made it much larger. It was a range of 1,300 feet in length, with an average breadth of 50 feet, and a height of 60 feet.

Mr. Cowper did not consider himself an authority on ventilation; but in certain engineering cases, when erecting Engine-Shafting, \&c., he believed he might say he had been called upon to ventilate a building, and had succeeded tolerably well. The old Post Office and the Inland Revenue Office were two of the largest buildings with which he had been concerned. It appeared to him that some 
of the conclusions of the Scientific Committee who went into the matter theoretically, were in fact old ideas, and some of the novel ideas were found to be impracticable, and had not been carried out. In several cases there had been something like a division by 3 , which rather tended to interfere with any scientific conclusion. No donbt the Author had treated the matter in a thoroughly practical way, and perhaps had neglected some of the theoretical conclusions. Had he been given a clear field, with full liberty to ventilate and warm the building as he liked, without the interference of so many persons, he would no doubt have done it at a much less cost than $£ 17,000$, and $£ 500$ a year for maintenance, coal being only 13s. a ton. The Author had not followed General Morin; nor had he adopted the quantity given by the committeo of 0.6 cubic foot of air per second for each individual. The area of opening was to have been $\frac{2}{5}$ square foot, but that being impossible it was practically carried out at $\frac{1}{18}$ square foot. The Author was to be congratulated on having arrived at such satisfactory results. As to the extent there might be differences of opinion; a quantity of fresh air had been obtained, and although some of the rooms were a little too warm, that no doubt could be remedied. A crowded class-room, where a popular professor was lecturing, was very different from one nearly empty; if air of the same temperature were pumped into both, one would be at fever heat, while the other would be only just comfortable. If, instead of raising all the rooms to a temperature suitable for an empty one, the fire was let down, and a lower temperature was made the rule, the heating of the cooler rooms could be easily supplemented by a few coils of pipes round them. Perkins's hotwater pipes were the most convenient, because they could be carried almost anywhere around the walls, and be run into the window recesses, and thus tended to prevent the cataract of cold air that often came down so unpleasantly from walls and windows in frosty weather where there was no apparatus. Although so many eminent names had been mentioned in the Paper, that of Dr. Arnott and Dr. Reid, both of whom strongly advocated forced ventilation, had been omitted. With regard to the construction, there appeared to him to be two complete systems. First, there was an elaborate system of flues below the bottom of the building. Of course full possession of the basement was necessary for that. He presumed that orders had been given to the architect to carry out the system, or he would not have subjected the walls to such severe treatment. That being granted, and the money assured, there was a complete system of hot air to come up all the 
vertical flues. With a fan, or any mode of forcing air into a room, it appeared to him that almost all difficulty of ventilation vanished. The late Mr. Oldham, of the Bank of Ireland, when managing the bank in Dublin put up a large wooden pump, with a leather packing, by which air was pumped into the printing office. When the cholera was raging in the neighbourhood, he used to say that he pumped it out of the windows, and in fact, no cases occurred in the building, which was thoroughly ventilated and wholesome. He had carried out the same plan at the Bank of England. By means of a pump, 4 feet square and of 5-feet stroke, air was pumped into the building. It was a favourite idea of Mr. Oldham to put a pocket-handkerchief saturated with Eau de Cologne in the passage, when the scent would be at once perceived all over the printing offices, showing that there had been a complete distribution of the air. Some years ago Mr. Cowper was consulted about a Town Hall, where the inconvenience of the cold air pouring down from contact with the windows was so marked, that in the gallery, where the best and most expensive seats were placed, the temperature during a concert was $42^{\circ}$ Fahrenheit. He suggested, as a temporary expedient, a row of gas jets on the window-sills : these had the effect of preventing the cold air from coming down, but it did not warm the hall, nor was it intended to do so. The evil was local, and required a local cure. Unless warm air, hot water, or gas were applied near the windows, cold air would assuredly come down from them. With regard to the advisability of the chamber underground being kept dry, he agreed with the Author of the Paper; but it appeared from what had been stated, that the chamber was damp. He might mention that the late Sir Charles Fox allowed a draughtsman of his to arrange a warming apparatus for his offices at Smethwick. Unfortunately, there was a flue underground in a gravel bed, which was very wet, with a sloping field down to it-also a gravel bed. The flue could not be dried, and the moisture continually evaporating from it into the offices, the water condensed against the windows, which had fixed cast-iron sashes with small openings, so that instead of the apparatus being a ventilating one, it was a distilling apparatus: the water ran down on the window-sill, and there were puddles half a yard square on the floor. The effect upon the health of the draftsmen was most injurious; and colours, such as Prussian blue, which was rather brittle when dry, could be bent without breaking. In summer, it became a habitation for frogs, and when the steam was turned on, there was "an ancient and a fish-like smell." In a large building where power could be 
used, there was little difficulty in applying hot-water pipes̀ in each room so as to have as much heat as was required in each placenot too much in one, or too little in another. The foul air could be blown out through the cracks of the windows and the doors, and if they were not enough, perforated zinc could be put on the tops of the sashes of the windows. The benefit of a little pressure in the room was that all draughts of cold air from the windows and doors were prevented. If they were excluded, by forcing ont the foul air instead of allowing the cold air to be drawn in, it was a great comfort. By using an extracting shaft, as in a coal pit, a partial vacuum was made in the room to draw out the foul air, and the advantage of preventing cold draughts was lost. Besides, the expense of the flues was doubled, and much eoal had to be burnt. In that way the candle was burnt at both ends, by sucking out the foul air whilst the fresh was being forced in. If the fresh were forced in, the foul must go out. Where gas-lights were largely employed, as in workshops, it was worth while to put small funnels over the top of the burners, taking pipes from them into the chimneys. That had been done in the underground offices of the Post Office, where gas burned continually; and in that way the products of combustion were carried off. With regard to the table at the end of the Paper, he observed that the temperature in the majority of the rooms was below $53^{\circ}$. This, he thought, was too low for comfort. The rooms in the morning ought to have a temperature of not less than $60^{\circ}$, and the artificial heat should be lowered when the natural heat of the bodies of the students came into play. Possibly, however, notwithstanding the enormous amount of hot-water piping, the large quantity of air pumped into the rooms might keep down the temperature, so that it was not practicable to get it higher than quoted in the table. He had observed the effect of a pair of large screw fans going in opposite directions, and the current produced by them was very feeble. More work could be obtained by a centrifugal fan. He had made three hundred experiments with centrifugal fans, and found that at low pressure not more than 50 or 60 per cent. of useful effect could be obtained; but at somewhat higher pressure he had obtained $75 \cdot 16$ per cent.

He desired to say a few words on what appeared the simplest mode of artificial ventilation without incurring excessive expense. First, the air should, of course, be drawn from the purest source available. A large roof on the top of the building without chimneys near was a good place from which to get air, the air in the streets being vitiated. Secondly, there should be a centrifugal 
fan in a convenient situation, near the engine, not necessarily in the middle of the building. The fan should draw the air from the best source, and drive it at a moderate velocity through medium-sized pipes, which he would call high-pressure mains, which should be always charged. Air could then be sent to any part of the building. All that would be required would be to draw off from the main as much air as was wanted for each room by a distribution pipe, full of holes, which could run round the skirting, or along the cornice or on the floor, and through which the air would ooze into the room without producing a draught. The distribution pipes must not have large holes in them, but $\frac{3}{4}$-inch holes, at intervals of an inch or two. Professor Faraday many years ago showed that a velocity of 2 feet per second did not produce a perceptible draught. This could be seen by taking a sheet of tracing paper and moving it through the air at that velocity, in which case it would take an angle of $45^{\circ}$ from the vertical, and without any draught or unpleasant effects being produced. The way to regulate the air to each distribution pipe from the main was to provide an opening from the main into the distribution pipe, and supply it with a small slide, and when the right quantity of air was provided, then to solder the slide fast. In that way the right quantity would be obtained for each room. A piece of tracing paper could be put in front of a hole, to show the pressure by the angle at which it stood. The velocity of the air in the mains might be 50 or 60 feet per second. In the Glasgow University it was only 11 or 12 feet, no doubt because the Author had graduated the size of the pipes and the velocity of the air, since there was a free opening from the fan into the room. Mr. Cowper had not got that arrangement by his system. He had the means of throttling the air under pressure from the main into the distribution pipes, which gave a power of regulation, and saved the expense of large passages and culverts, and of cutting the walls so much and making large shafts. A pipe 1 foot square, or so, could be introduced into the corner of a building without great expense, and the cost was less.

Fig. 2 showed a fan for ventilating the stamping department of the Inland Revenue Office. The whole of the blades could deliver air at all times throughout their revolution, the spiral outline of the casing starting from the bottom, at the circle formed by the tips of the blades, and gradually opening out, as an arithmetical spiral, to the width of the mouth of the fan. The corner was rounded, to prevent the air meeting a sharp edge. In this way a perfectly silent fan was formed, and one capable of propelling a 
large quantity of air. Captain Ericson had set out fans very like this forty years ago. Mr. Cowper had constructed many of them. He had made about three hundred experiments with one large fan; in some of the experiments there was a central curved boss, and in

FIG. 2.

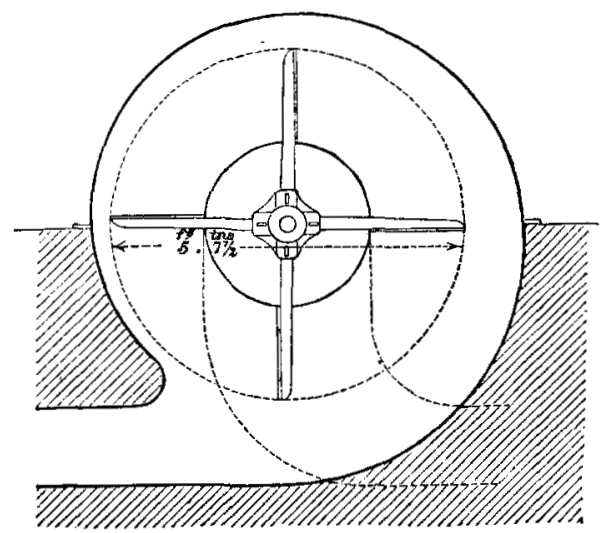

others, screw blades on each side in the eye, neither of which were of much use. The percentage of useful effect varied much with different pressures up to one equivalent to a column of water of 9 inches, and varying areas of opening. In some cases, the percentage of useful effect, calculated by the area of opening, and the velocity due to the pressure at the exit, amounted, as had been stated, to $75 \cdot 16$ per cent. of the power expended, which power was calculated from the average of three good indicator diagrams in every case, the velocity of the air being about $\frac{9}{10}$ of the velocity of the tips of the blades.

Mr. ImRaY remarked, through the Secretary, that more than thirty years ago he had been engaged in a great number of works of warming and ventilating, having been at that time associated with one who might be called the Apostle of Ventilation, Dr. Boswell Reid. The works referred to included the State apartments of Buckingham Palace; the Italian Opera in the Haymarket; the prisons of Perth, Edinburgh, and Belfast; St. George's Hall, Liverpool; the Industrial Schools at Swinton, near Manchester; the Royal yachts; sereral hospital ships; the Courts of Law at Westminster and the Old Bailey; and the Houses of Parliament.

The Author had truly said that there were no physical difficulties in the way of ventilation, for air, like any other inert body, would go in any required direction by the application of suitable 
force. The real difficulties encountered by the engineer who undertook warming and ventilating works were of what might - be called a moral kind. The first of these arose from the fact that the warming and ventilation of a structure was almost always an afterthought. The plans were completed, often the structure was far advanced, or even finished, before a thought was given to arrangements for making it comfortable and salubrious. It then became almost impossible to carry out desirable modifications without materially interfering with the accommodation and design; and the engineer was, therefore, driven to do the best he could under the circumstances, though that was far from the best that he could do if left untrammelled. The next difficulty of the moral order which the engineer had to encounter, a difficulty that presented itself even when ventilation was studied $a b$ initio, was to prevail upon the architect to subordinate beauty to utility. Because an air-chamber might lower a ceiling a few inches, because an airinlet might involve certain perforations, or an air-outlet might require a hole, the architect would condemn the tenants of his structure to discomfort and suffering, holding them to be amply compensated by elegant proportions or tasteful decorations. It was undoubtedly the civil engineer who had taught the architect that the structure must, in the first place, be fully suited to its purpose, and might then, in the second place, but not before, be made to look pretty. And it was only since the engineer had given the example of structures eminently fitted for their purposes in respect of accommodation and strength, and at the same time stately and beautiful, that the architect had condescended to bestow nearly as much consideration to the useful as he had hitherto done to the beautiful. At the time when he was engaged on works of the kind referred to, there was an incessant struggle against the notion that a thing could not be made to look well if it also acted well. Another difficulty, also of the moral kind, in the way of successful ventilation, consisted in the impossibility of satisfying everyone. For several years he had superintended the ventilation of the temporary House of Commons, which was occupied while the new building was in course of erection. The ventilation of this chamber was acknowledged to be absolutely perfect, the engineer having had perfect freedom of action in carrying out his plans. The air supplied was sifted, washed, partly warmed, mixed and tempered, and admitted to the House in a gentle and uniformlydiffused stream; it could be supplied in almost any desired volume, and at almost any desired temperature, within reasonable limits, and suited to a House composed of thirty or of five hundred members. 
But with all this it was impossible to satisfy many of those for whom such provision had been made. One member perhaps complained of cold, while his neighbour complained of overpowering heat. In the midst of these difficulties the Speaker took the matter in his own hands, gave orders as to the temperature, and those orders were strictly complied with.

If a chamber or building had no pretentions to ventilation, its occupants did not complain, because they knew it was bootless; but the moment it was said to be scientifically ventilated everyone complained because the climate was not exactly what he desired. It might thus be readily understood that ventilation, as had already been remarked during the discussion, never got the credit of succeeding. Those who were satisfied did not care to express their content, they took it all as a matter of course; while the discontented minority cried aloud and led the outside world to believe that the whole thing was a failure.

With respect to the particular work under consideration, the warming and ventilating arrangements of Glasgow University, the engineer had evidently been hampered by some of the diffculties above referred to, and would probably have done some things differently if he had been free to choose. It could not be supposed, for instance, that he preferred to employ as fresh-air conduits, channels underground, subject to damp and to noxious emanations from sewers. He undoubtedly did right in taking fresh air from a high elevation, and in forcing it by a fan or propeller. As Mr. Cowper had justly remarked, a slight elevation of the pressure in an inhabited apartment had the beneficial effect of preventing all in-draughts, and making sure that the only air supplied was that which could be controlled and tempered as desired. The plenum supply presented also another advantage, likewise referred to by Mr. Cowper, that it rendered unnecessary special arrangements for the discharge of foul air. Force a proper supply in, and provide outlets for discharge, and the climate of the room might be controlled as desired.

Whether fresh air was supplied under a little pressure, or whether foul air was extracted by slight rarefaction, as by a chimney draught, or whether both these forces were applied together, there must always be a difficulty about the arrangement of the actual fresh-air inlets. As a matter of necessity, if these were near the occupants, they must be of very large area, otherwise there would be such velocity of flow as to give the current the character of a local draught, alike unwholesome and unpleasant. The currents also must be broken up and dif- 
fused, so as to provide a slow and gentle exchange of air without any perceptible movement. In order to provide for this in some cases, as in the temporary House of Commons before referred to, the whole floor had been perforated and covered by a thick hair carpet of loose texture. This perfectly served the purpose so far as regarded diffusion and suppression of currents. The only objection was that there would always be deposits of dust from the feet of the occupants, and it was not desirable that the fresh air supply should become vitiated at its very ingress. Where there were steps or stages of various elevations, or vertical screens or partitions, a well diffused supply could be obtained by making their surfaces porous, as in the form of gratings with some open fabric behind them; and in an apartment of moderate dimensions the whole supply might come through a porous skirting presenting a considerable surface. This, in his experience, had proved by far the best means of providing a supply of air for an apartment. The vertical surfaces did not harbour dust and dirt like the horizontal surfaces, and they were usually distant by a few feet from any of the occupants. Unfortunately architects had almost insuperable objections to open work at the base of a wall; they had not yet learned to look on it as a necessity, as much as a door, window or fireplace; and until they did so, they would not endeavour to make it ornamental as well as useful. It was probably in consequence of the difficulty of getting such open work at the lower level, that the Author, as well as other ventilating engineers, had had recourse to fresh-air inlets at a high level. This, in his opinion, was a grave error; and he only ventured to say so after many experiments of the kind referred to by Professor Thomson, which had satisfied him that such an arrangement was worse than useless. The emanations from the body, as well as the products of combustion from lights, were always warmer than the surrounding air, and must therefore rise. If while they rose the fresh air was descending, it must mingle with them and become contaminated before it reached the persons who were to breathe it. If, on the other hand, the air supplied was itself warm, it would ascend along with the foul air, and never reach the persons for whose use it was provided. It was a fallacy to suppose that because the inlets were removed to some height above the occupants the inflowing currents would be broken and retarded by diffusion in their descent; for, if the supply was colder than the air in the room, it would descend like a cataract from the inlet, and, if it was of equal or of higher temperature, it would never descend at all. 
With the exception of the arrangement that had been adopted for fresh-air supply to the individual rooms, the Author's plans, as carried out in the Glasgow University, appeared to be well designed, and should be successful so far as success could be attained in any such work. In a work in which he had been recently associated with the Author, every credit was due to him for the way in which he met and overcame very serious difficulties; and probably if the Author had been more free in dealing with the Glasgow University there would not have been any ground for some of the objections that had been raised to his plans.

Mr. ThornycrofT said that the warming and ventilation of the Glasgow University had presented great difficulties, in consequence of the long channels employed. He quite agreed with $\mathrm{Mr}$. Imray with regard to the great advantage of having a slight excess of pressure in the building. He observed that the ratio of inlet to outlet had been made more uniform than had been suggested by the Committee who examined the subject before the building was erected. The inlet was to have had twice the area of the outlet; and it appeared to him that that ratio was partly intended to produce a slight excess of pressure within the building, compared with that outside. $\mathrm{H}_{\theta}$ thought that the recommendations of the Committee should have had the most careful consideration, as they had investigated the subject very fully. In considering the intention of the Committee, it appeared that, first of all, the pressure in the building should exceed the external pressure, and that the temperature of the air should be independent of the rate of change; that any room should be capable of having any amount of air passed through it, still maintaining the temperature at one definite point. Apparently the intention was that the hot air should remain first at the top of the room, and, as it cooled, gradually descend, so that the noxious air should be drawn out from the base of the room. That would probably be the effect if a room was heated by the air passing through it. With regard to the shortness of the conduits, where a room was self-ventilating-where there was an accidental ventilation-the channels were usually short, the air always taking the shortest way. It should always be borne in mind, in designing a ventilating apparatus, that the channels should either be short or large. He begged to offer a sketch of what appeared to him to be a way of overcoming the difficulties of the building. He should require a large corridor, say 10 feet wide by 15 feet high, branching to the various parts of the building, and his scheme would be to use it as the channel 
of air, and so to do away with all underground channels, with the exception, perhaps, of a heating chamber at the base of the tower. The air would then be passed through the channels at a velocity of $1 \frac{1}{5}$ foot per second, with three channels leading to different parts of the building, taking the supply of air, as mentioned in the Paper, at 500 feet per second. If the building were heated by hot water or otherwise, so as to maintain the desired temperature independent of any change of air, any amount of air at the desired temperature could be forced through any part of the building without affecting the temperature. There might be difficulties in diffusing it so as not to make a draught, but he thought a slow current would not be any great obstacle in the corridors. There was one point in the Paper which had attracted his attention-the difference between the wet and dry bulb thermometers. He was not sure whether it was meant to maintain the same difference of temperature at $100^{\circ}$ as was stated at $60^{\circ}$; but he thought it probable that a higher difference would be necessary.

Mr. SHoolbred said that the Author had quoted two or three common axioms, such as that "Air has a tendency to rise," "Cold air cannot rise," as "errors of judgment, based upon false notions, and leading to uncertainty and confusion." In questions of practical ventilation, there were other matters besides statements of that kind, which were in themselves correct-other natural forces coming into play, which considerably modified the mode of treating. the question of the air; such as were caused by the introduction of persons into the rooms that were ventilated; the exhalationsfrom those persons, together with the illumination of the rooms, introducing a counter-current of hot air which had a tendency to rise. According as the system of ventilation employed was downward, as in the case described, or upward, as was more generally the case, the force created by persons in the room either became an assistance in the ventilation, or an obstacle, and one requiring considerable artificial force to overcome it. The counter-current introduced in downward ventilation must not simply oppose, but. be of such force and character as completely to sweep away the rising stream. That this had hardly been the result in the Glasgow University, as had been intended, was borne out by the very naïve admission made in the Paper, with reference to certain of the classrooms. It was stated that, "in the medical and other class-rooms, which are used early in the moming, when much gas-light is required, openings for exit have been provided near the ceiling, in addition to those perforations" (the ordinary exits placed in the risers of the seats): the entrance for pure air being near the [1878-79. N.s.] 
ceiling, not very far from where the extra exits had been provided. What then might be anticipated as the result? The fresh air coming in not far from the ceiling was intended to be deflected downwards, and to pass out at the openings near the risers; but it was almost immediately subjected to the upward tendency of the heated emanations from the gas-lights towards the additional outlets; it was also affected by the heated atmosphere arising from the exhalations of the persons assembled; consequently very little of the pure air came downwards; it was sucked up by the extra openings. That view was borne out by the experiments of Professor James Thomson. By means of the smoke from burning flax or cotton, such as Dr. Reid used to employ, it was ascertained that the lower stratum of air occupied by the audience formed a nearly stagnant mass. The only action upon that mass would be the extracting influence from the ventilating shafts drawing through the outlet openings in the risers. The audience, therefore, instead of being in pure air, would be sitting in air becoming more and more vitiated every moment.

He was far from saying that downward ventilation was not applicable, and that there were not cases in which it might be fairly successful; but its difficulties were enormously increased when there were large bodies of persons to be dealt with, and particularly where the heat from the illuminants was allowed to pass freely into the room. In a room of considerable dimensions, with upward ventilation, the natural reservoir in the upper portion acted as a receptacle for the foul air, allowing it to be removed immediately from the audience. With downward ventilation, however, unless it was remarkably effective, the cold air remained at the top of the room, while the stagnant and foul air kept unfortunately below, around the persons assembled there. A short time ago he was present at the Conservatoire des Arts et Métiers, which was supposed to be the type application of General Morin's system by himself. The system of downward ventilation had been carried out there. However, he could himself state, that when, a few months ago, during the meeting of the Institution of Mechanical Engineers in the large amphitheatre of that building, he was sitting on one of the benches at some height above the floor of the room, he felt a considerable and unpleasant inward draught from the gratings in the risers, which, if there had been a downward ventilation, would have been intended as exits.

The Author had mentioned that an average allowance of 750 cubic feet per hour had been taken as the basis, in accordance with the views of "well-known authorities." The amount for 
consumption during the day, as stated by modern authorities, was considerably in excess of that amount. General Morin, in his experiments, especially since the construction of the hospital of Lariboissière in Paris, considered that for almost all buildings at least 1,000 cubic feet per head per hour during the day should be allowed, and for night purposes 2,000 cubic feet. Dr. Parkes concurred in the latter figure; and, as far as he himself could ascertain, it appeared to be generally acknowledged as the fit and proper allowance under ordinary circumstances. Dr. Reid, who was probably the authority referred to, partly if not entirely, by the Author, though he placed the minimum at 600 cubic feet, provided on some occasions a maximum of six times that amount. His ventilating arrangements in the House of Commons, though they had been altered very considerably by his successor, Sir Goldsworthy Gurney, and also under Dr. Percy, as well as those in St. George's Hall at Liverpool, where Dr. Reid's original arrangements remained much more intact, the allowance of air was much larger than 600 cubic feet per head per hour.

If an allowance of 750 cubic feet per hour was not sufficient during the day, it was wholly insufficient for night purposes; especially if gas-lights were employed and were burnt naked, as was the case, if he remembered aright, in most of the class-rooms of the Glasgow University. The amount of air generally acknowledged to be sufficient to dilute the products of combustion was nearly 2,000 cubic feet per hour per cubic foot of gas consumed, and that represented about the allowance to a single person. Mr. Cowper had mentioned that it was worth while to place pipes directly over the gas-jets, in order to carry off the products of combustion. Indeed, in many large rooms where numerous naked gas-jets were used, the supply of air required for the proper dilution of the gas products was in most cases equal to, and in some more than, that necessitated by the audience in the room. It might be interesting to the meeting to give a somewhat forcible example on that point-the example afforded by the room in which they were assembled. The result was so striking that it was worth mentioning. The room was 61 feet long, 39 feet broad, with an average height of 33 feet. Its cubical contents were somewhat over 79,000 feet. It would seat, he was informed, about three hundred and seventy-five persons closely packed. A full attendance might be taken at three hundred. At 2,000 cubic feet each, they would consume 600,000 cubic feet of air per hour, or $7 \frac{1}{2}$ times the cubical contents of the room; so that in order to get that supply the room would have to be filled $7 \frac{1}{2}$ times 
during the hour, the allowance in Glasgow being 6 times. The gas-lights were: a central sun-burner, with seven stars of eight jets each ; and two side-burners, each consisting of a central eightjet star, surrounded by a circle of twenty simple jets. The three sun-burners being placed close to the ceiling, each had its own waste pipe directly over to carry off the products of combustion, and, by the increased temperature caused around it, to aid in the ventilation of the lower part of the room. But, had all those gasjets been left naked and distributed about different parts of the room, what would have been the case? Those one hundred and twenty burners each consumed about 3 cubic feet of gas per hour, or a total of 336 feet in an hour. Two thousand cubic feet of air to each cubic foot of gas would give 672,000 cubic feet of airan amount exceeding that required for a full room, and more than double the amount required for an audience such as that then assembled. Of course, the amount of force of air required simply to carry off the products of combustion, not to dilute them, would be enormously less.

In connection with that subject he might mention the great advantage which the new illuminant, the electric light, possessed in that respect, since it was generally supposed to require no special supply to carry off or dilute any deleterious products of combustion; and, in regard to raising the temperature of the room itself, the advantage it afforded was even more striking. The luminous point of the electric light was very small indeed. Probably in comparison with an ordinary gas-jet, it did not present one quarter of the heating surface; and, judging from the actual result in those cases where illumination by electricity had been in regular use for several years, fifty, eighty, or perhaps one hundred gas-jets might be effectively replaced by one electric light, which would certainly give a diminished heating area of about $\frac{1}{2} \frac{1}{0} \delta$ part of that presented by the corresponding illumination by gas. So that the amelioration effected in a sanitary point of view, by electric illumination, would be considerable. The fresh air for the Glasgow University was stated to be taken from a height of 100 feet, where it was considered to be "pure" and "far from all local causes of contamination." It might be of interest to mention, that Dr. Reid took the air supply for the Houses of Parliament from a somewhat similar elevation. After being in operation for sereral years, doubts were thrown on the purity of this supply. Experiments upon the air taken at this elevated level, and also upon that taken from near the ground, on the river terrace, by means of intercepting screens of thin material, showed conclusively 
that the upper air was charged with a much larger proportion of sooty matter, and of particles of road-dust, than it was at the lower level. The fresh air supply at the Houses of Parliament has, therefore, for some years been taken from the latter source.

He hoped the Author would not consider that his remarks were intended to depreciate the value of his Paper, or of his design; because it was evident that, from the commencement, the data of the system and the arrangements for ventilating were imposed upon him by the members of the Committee, who had no doubt carefully considered the subject beforehand.

He might be permitted, in conclusion, to mention one recent case in which downward ventilation had been successfully applied - that of the hall of the Trocadero Palace at the recent Paris Exhibition. Hitherto it had only been used in the day. It remained to be seen how the system would act at night, when the extra heat arising from the illuminants came into play, which was especially the test of downward ventilation. During the summer months of the Exhibition every one had, however, seemed well pleased with the result. The room was calculated to seat five thousand persons, and there was an hourly allowance of upwards of 7,000,000 cubic feet of air-1,400 cubic feet per head. Both for the inlet and for the extraction of air mechanical means were used. An 8-bladed screw fan was employed in both cases, 11 feet 6 inches in diameter, and 2 feet wide. The centre of the fan was blocked off by a truncated cone. The inlet fan was driven at about ten revolutions a minute, and the exit at nine; so that there was a slight excess of pressure within the hall, such as Mr. Imray and others considered to be advantageous in excluding draughts from the outside. The speed of the air at the inlet fan was 13 feet per second; whereas at the inlet mouths in the hall it was 20 inches, and at the outlet mouths only 16 inches. The fresh air supply was a double one, and might be taken, as needed, either from above the top of the roof of the building, or from the old quarries of the Trocadero (which were now covered over and formed part of the gardens). As the mean annual temperature of the latter source was almost constant, about $54^{\circ}$ Fahrenheit, the air taken thence might be used either to warm, or to cool, that taken directly from the external atmosphere by the upper source. The whole of the fresh air was passed to the inlet fan in the basement of the building, and previously warmed when necessary: it was thence propelled up a shaft to the top of the hall, into which it descended throughe a large circular central grating in the ceiling. The outlet mouths, 5,000 in number, were placed one at each sitting; but extending 
high enough in the back of each seat to be above the level of ladies' dresses. Considerable care was taken in arranging the course of the outlet pipes to the exhaust fan, situated also in the basement, so that the distance from each mouth to the fan should be the same. In this way the suction draught was equalised at all the outlets. The exhaust fan propelled the foul air up a chimney to the central lantern above the hall, whence it escaped into the external atmosphere, but at a considerable distance from the high level inlet of the fresh air. The preceding particulars and explanations had been kindly given him at the building by M. Bourdais, the joint architect with M. Davioud.

Mr. SchöNHEYDER remarked that, in arranging a system of ventilation such as that required for the Glasgow University, it was highly necessary to distinguish between summer and winter ventilation.. In winter, warm air was needed, which should, in most cases, be supplied from above, and allowed gradually to descend, and to be abstracted at the lower part. In summer, cool air was necessary for a room where a great number of persons were assembled; and it should be in most cases supplied at the lower part of the room, and abstracted at the top, so as to allow the natural force of gravity to assist in ventilation instead of opposing it. By acting in a contrary way, there would generally be currents. If cool air were admitted at the top it would descend with a certain amount of force, and cause draughts; if warm air were admitted below, it would certainly be forced up to some extent, but portions of it would come in contact with the cooler walls, and then descend, so that the vitiated would be mixed with the fresh air, and the room, though partially, would not be successfully ventilated. Engineers differed very much upon that point, and many buildings were constructed in opposition to those suggestions. He had been obliged to ventilate rooms by an upward current where he considered a downward one would be better; and he had found that in such cases the air in certain parts of the room was not as pure, and the temperature was not as evenly distributed, as it ought to be. A good example of ventilation, on a small scale, upon the system to which he had referred, was the Galton stove. By that arrangement warm air was supplied to the upper part of the room; it was allowed gradually to descend by being cooled in contact with the walls, and it was withdrawn at the lower part of the room. It had been properly remarked by Mr. Cowper and others that ventilation by forcing air into the room was preferable in most cases. If the air were obtained from a pure source, there would be a pure 
supply to the room; but if the room were ventilated by suction, the air might come from an impure supply, as was the case in many private houses where there were in-draughts of impure air, causing disease and death. There need not necessarily be any complication in the system, because the downward current could be adopted in one instance, and the upward one in another. If proper channels were supplied near ceiling and floor, they might be used alternately for the supply of pure air and the withdrawal of vitiated air, by a simple arrangement of valves which might be changed. In some cases, such as for libraries, other systems had to be adopted, more warmth being required and less air. The quantity of air to be supplied varied from 500 cubic feet per person per hour to $2,000,3,000$, and in some cases 4,000 cubic feet. It was stated by different authorities that the amount of heat given out by human beings, owing to the combustion going on inside them, varied from 200 to 500 units per hour. The whole of that heat had to be carried off; and if 1,200 cubic feet of air were supplied per hour per individual, taking the specific heat of air at $0 \cdot 238$, it would be found that to carry it all off the air would have to be raised $23^{\circ}$ in temperature, supposing that the walls were neither receiving heat nor giving it out. That was an excessive case, but it showed the necessity of supplying a large amount of air, especially for summer ventilation. He thought that the estimate of 500 units was too high. The screw propeller which the Author had adopted to supply air to the room was, he considered, a very wasteful instrument. It had the fault of the ordinary screw used in vessels-the slip. He had made experiments upon screw tugs, and had sometimes found the slip as much as 75 per cent. From the data given by the Author, it appeared that the slip of the screw was no less than 80 per cent., which meant that it not only propelled the air forward, but also gave it a rotary motion, and all the power consumed in that rotary motion was of course lost. It might be taken up by properly constructed guide-plates; in fact, the instrument might be improved as shown in the fan described by Mr. Cowper. Those fans were at one time made, and seemed still to be made, with casings concentric with the fan, which allowed the air to be twirled round and round before it was discharged, so that there was a great loss of power. In calculating the friction of resistance of the air channels, the Author had taken the mean of the velocities in all the pipes, the mean of the diameters, and of the circumference. That was a most extraordinary method, and the result arrived at was absurd -a resistance of only $0.04 \mathrm{inch}$, which was, of course, far tou low. 
Fach channel should be calculated separately as to the dimensions and the velocity of the air through it.

Mr. Rivers said that the question of what was the best hotwater boiler for an apparatus like that at the Glasgow University was one on which very different opinions had been expressed by engineers; but he believed it had been long established that the tubular principle possessed special advantages with regard to rapidity of heating. Owing, however, to the defects hitherto associated with the tubular system-the choking of the tubes, the deposition of sediment, and the defective circulation-the system had not hitherto met with the favour it deserved. Some considerable experience in the working of hot-water boilers at the Royal Gardens, Kew, had led him to make some experiments, with a view to designing a tubular boiler which should be free from those defects, and the result was shown in Figs. 3 and 4. The improved

FIG. 3.

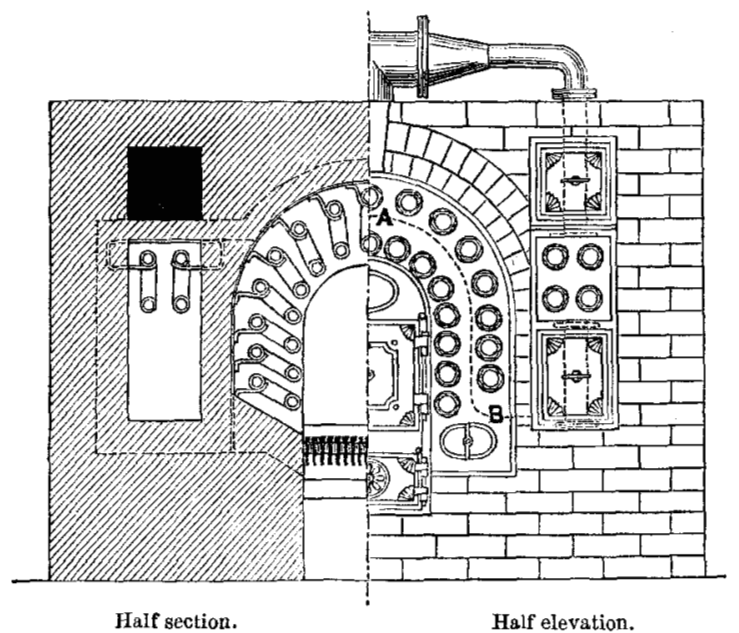

The position of the diaphragm is shown by the dotted line A B.

boiler consisted of pairs of wrought-iron tubes, arranged in a horseshoe shape, and connected to a circulating chamber. The leg of each tube passed completely through the chamber, and the connection between the tube and the chamber was secured by a slotted aperture. The chamber was divided into two compartments by a diaphragm, and it would be soen that a very rapid circulation must take place in the tubes. It had been found, after the experience of a year's work, that the tubes were completely free from deposit. 
One of them had been recently taken out at Kew, and it was as clean as when it was first put in. One feature of the boiler was the readiness with which repairs could be effected. Any tube could be removed by simply unscrewing a hexagon nut on the face of the chamber, and no portion of the brick seating needed removal. It had been admitted by the authorities at Kew that

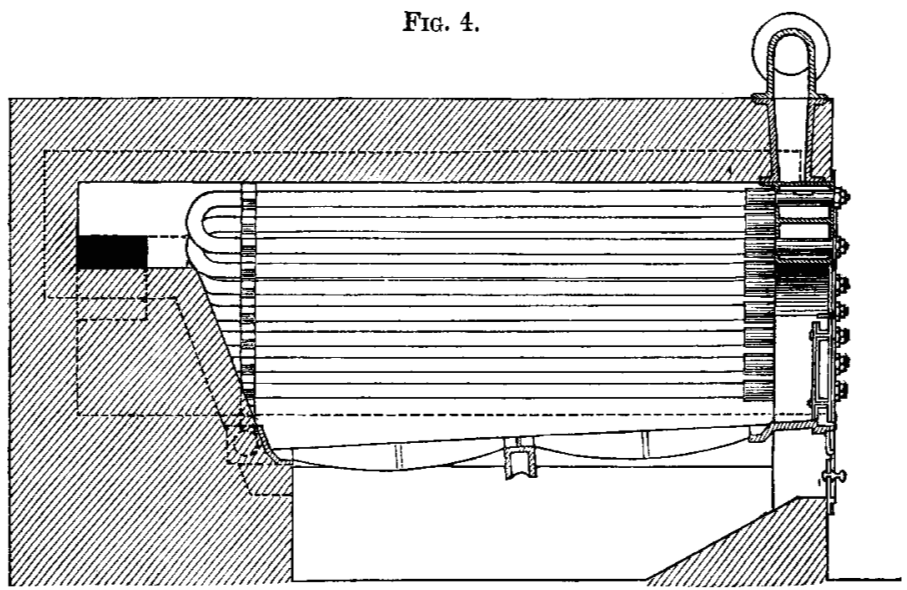

Longitudinal Section.

all the defects hitherto attendant upon the tubular system had been obviated by the contrivances mentioned. Six boilers of this pattern were fixed in the palm-house at Kew, and, except in very severe weather, not more than four were in use at one time. The length of pipe heated was 19,480 feet, the area of fire-grate for four boilers was 36 square feet.

Mr. Phipson, in reply, said that the views expressed by Professor James Thomson were not entertained by the majority of the Professors in the University. It need not be a matter for wonder if there were some individual defects in so large a scheme, owing to the great variety of conditions. In some instances, perhaps, failures might have arisen from the means employed being inadequate to compensate for the larger number of students than was at first contemplated. He was now engaged in endeavouring to remedy these defects, and hoped, with the assistance of the Professors, to succeed in doing so. In reference to the omission of the provision for introducing the supply hot or cold, contained in Clause 5 of the Committee's instructions, he might mention that means already existed, not described in the Paper, 
for passing part of the fresh air direct to the several rooms, without having to traverse the heating chambers. It might be admitted, but for the difficulty of construction, that there would be an advantage in that provision being increased in greater detail. The amount of moisture in the warm-air distributing channels, referred to by Professor James Thomson, only occurred in one part of the building. Mr. Constantine's statement of the power and action of the air warmers might be correct; but when he asserted that had they been applied to the building in question the cost would only have been $£ 1,600$, his announcement, without further details, ought to be taken with great reserve. But irrespective of that, he much doubted their application to a building of such magnitude, with so many conditions to be fulfilled, especially as to the quality of the air to be supplied. The amount of fuel consumed in an apparatus planned for the heating of one or two spaces in a compact building like the Free Trade Hall, or the Exchange at Manchester, could not be classed in the same category with an application in which the heating surfaces were distributed over a developed frontage of 1,300 feet. In illustration, he might mention that the apparatus planned by him for the Royal Albert Hall, Kensington, in which the space to be warmed, and the number of feet of heating surface, if anything, were in excess of the University apparatus, the consumption of $25 \mathrm{cwt}$. of coals per day was ample to maintain the temperature, even in severe winter weather, from $20^{\circ}$ to $25^{\circ}$ Fahrenheit above the external temperature, in lieu of the $45 \mathrm{cwt}$. consumed under similar circumstances in the Glasgow apparatus. Tarious causes had contributed to increase the annual cost of the maintenance of the application in question : the exposed position of the building, the large cooling influences of the stone walls, the numerous staircases and passages opening direct to the external air, and the subsoil of the building being clay. The temperatures of the several class-rooms quoted in the appendix did not show the maximum working power of the apparatus; they were temperatures found by experience to meet the requirements at 8 A.M. so as to ensure during the remaining portion of the day in the several class-rooms a temperature of from $57^{\circ}$ to $60^{\circ}$ Fahrenheit. It had also been found inexpedient to introduce a large body of persons suddenly from the external cold air into a room of which the temperature was $60^{\circ}$ Fahrenheit, although before the hour of meeting was over it might be allowed to attain that temperature. $\mathrm{He}$ could not confirm all Mr. Cowper's views on the supply and extraction of the air from a ventilated space, and practice led him to believe, that unless those two elements were satisfactorily 
combined, no dependence could be placed on any application for ventilation. The recent experiments on fans of different forms for ventilation lately made in France confirmed somewhat his views on that subject, since they had caused the adoption of the screw fan for the ventilating apparatus at the Trocadero Palace. There might however still be improvements in the application of motive power on the air, as had been suggested to him by having lately seen an ingenious contrivance of Professor James 'Thomson, by which, with the same wheel, both introduction and extraction of air might be effected. In conclusion, he might state, that in bringing that application of ventilation and warming of a large public building to the notice of the Institution, he had endeavoured to show how far, by mechanical power applied at one central point, a steady pressure, ensuring a velocity of delivery equal to from 3 to 4 feet per second, could be maintained over its entire extent.

Mr. Benjamin Verity stated, through the Secretary, that the internal mechanism of a ventilating machine devised and exhibited by him, consisted of a set of fans working in a drum, and fitted on the same axle as a flywheel. The flywheel was formed with a corrugated ridge on the outer edge, on which a fine jet or jets of water impinged, and, according to the hydraulic force, caused both wheel and fans to revolve with great velocity. The points of the axle worked in countersunk jewelled centres, and were also enclosed in metal cups containing oil for lubricating purposes, so that friction was reduced to a minimum. The water, after leaving the corrugated flywheel, was discharged across the inlet tube in the form of a shower or spray, to cleanse the incoming air before its passage through the machine. In the vertical discharge tube, also from the machine, the air was brought into contact with a coarse sponge, and was further purified previous to delivery into the room. This was particularly apparent in foggy weather, when the air pumped in was received perfectly clear. He preferred fitting the fresh air discharge-tube from the machine into the room, at about 5 feet 6 inches above the floor, and to extract the vitiated atmosphere at the ceiling. As the velocity of the fans and consequent power of the machine depended upon the amount of hydraulic pressure at command, in all cases where practicable it was advisable to derive this from the water main, or, otherwise, from a cistern placed at a suitable height. With 30 lbs. pressure, a current of air would pass through the machine at the rate of 1,000 lineal feet per minute; with increased pressure, a higher result might be obtained. In applying 
the machines for warming purposes, it was proposed to generate the warm air in a room, in the lower part of a building, by a series of hot-water pipes, or by a stove. From this room it was intended to carry a galvanised iron-cased tube, packed with felt or other material to retain the heat, to the room to be warmed. This pipe, however, should be arranged to rise as much as possible, and should have separate branches to each room, with an airpropeller fitted to each outlet for exhausting the air from the warm-air tubes into the room.

The machines were separately and collectively under immediate control. This plan had been adopted at the Reform Club, and other buildings. The machine exhibited was for extracting the foul air from soil-pipes; the inner mechanism was similar to the air-propeller on a reduced scale. It was worked by a single jet of water, and its object was to create a constant upward current in the soil-pipe for the ventilation of house drains, the opening of the discharge-tube being above the roof of the building.

For the ventilation of main sewers, he recommended a machine on the exhaust principle, in the form of a stand-pipe or lamp column. In the latter case the sewer gas should be directed through the column, and should be discharged into the lantern above. This lantern, being fitted with a number of gas-burners, the sewer air, in its passage through the flame, would be deprived of its noxious properties.

December 10, 1878.

JOHN FREDERIC BATEMAN, F.R.SS. L. \& E., President, in the Chair.

A Paper on "Railway Work in Japan," by Mr. W. Furniss Potter, M. Inst. C.E., was read at this meeting, but as the discussion could not then be taken, the publication of the Paper is deferred till the next volume. 


\section{ANNUAL GENERAL MEETING.}

December 17, 1878.

\section{JOHN FREDERIC BATEMAN, F.R.SS. L. \& E., President, in the Chair.}

ThE notice convening the meeting having been read,

Messrs. J. D. Baldry, C. Frewer, C. E. Hollingsworth, H. Law, R. C. May, T. M. Smith, J. Thomson, and A. Williams were requested to act as Scrutineers of the Ballot, for the election of the President, Vice-Presidents, and other Members of Council for the ensuing year; and it was resolved that the Ballot Papers should be sent for examination every quarter of an hour that the Ballot remained open.

The Ballot having been declared open, the Annual Report of the Council, on the Proceedings of the Institution during the past year, was read. (Vide page 175.)

Resolved,-That the Report of the Council be received and approved, that it be referred to the Council to be arranged for printing, and that it be circulated with the Minutes of Proceedings in the usual manner.

The Telford and Watt Medals, the Telford and Manby Premiums, the Miller Scholarship and Prizes, and the Howard Quinquennial Prize, which had been awarded, were presented. (Vide pages 192 and 193.)

Resolved,-That the thanks of the Institution are justly due and are presented to the Vice-Presidents and other Members of the Council, for their co-operation with the President, their constant attendance at the Meetings, and their zeal on behalf of the Institution.

Mr. Barlow, Vice-President, returned thanks.

Resolved unanimously,-That the cordial thanks of the Meeting be given to Mr. Bateman, President, for his persevering endeavours in the interests of the Institution, for his unremitting attention to the duties of his office, and for the urbanity he has at all times displayed in the Chair.

Mr. Bateman, President, returned thanks.

Resolved,-That the thanks of the Institution are due, and are 
presented to Messrs. R. Price Williams and Alfred Rumball, for the comprehensive statement of Receipts and Payments they have prepared; and that Messrs. Alfred Rumball and W. B. Lewis be requested to act as Auditors for the ensuing year.

Mr. Price Williams returned thanks.

Resolved,- That the cordial thanks of the Institution be tendered to Mr. Charles Manby, the Honorary Secretary, and to Mr. James Forrest, the Secretary, for their long and valued services to the Institution.

Mr. Forrest returned thanks.

The Ballot having been open more than an hour, the Scrutineers, after examining the papers, announced that the following gentlemen were duly elected:

President.

JOHN FREDERIC BATEMAN, F.R.SS. L. \& E.

Vice-Presidents.

James Abernethy.

Sir W.G. Armstrong, C.B., F.R.S. James Brunlees, F.R.S.E.

\section{Other Members of Council.}

William Baker (since deceased). Alfred Giles, M.P.

Sir Joseph Wm. Bazalgette, C.B. Harrison Hayter.

George Berkley.

Fred. Jos. Bramwell, F.R.S.

George Barclay Bruce.

Sir John Coode.

William Froude, M.A., F.R.S.

William Pole, F.R.SS. L. \& E.

Robert Rawlinson, C.B.

Charles William Siemens, F.R.S.

David Stevenson, F.R.S.E.

Sir Jos. Whitworth, Bart., F.R.S.

Edward Woods.

Resolved,-That the thanks of the Meeting be given to Messrs. Baldry, Frewer, Hollingsworth, Law, May, Smith, Thomson, and Williams, the Scrutineers, for the promptitude and efficiency with which they have performed the duties of their office; and that the Ballot Papers be destroyed. 